\title{
EXTRAÇÃO DE ÓLEO DE CHIA (Salvia hispanica L.) VIA SOHXLET
}

\author{
H. RISS ${ }^{1}$; T. K. CARNIEL ${ }^{1}$; C. F. FARINA ${ }^{1}$; A. K. ROSO ${ }^{1}$; L. L. SILVA ${ }^{1,2}$; J. M. M. \\ MELLO $^{1,2} ;$ F. DALCANTON ${ }^{1,2}$ \\ ${ }^{1}$ Universidade Comunitária da Região de Chapecó, Área de Ciências Exatas e Ambientais \\ ${ }^{2}$ Universidade Comunitária da Região de Chapecó, Programa de Pós-Graduação em \\ Tecnologia e Gestão da Inovação \\ E-mail para contato: heloisariss@unochapeco.edu.br
}

\begin{abstract}
RESUMO - A chia (Salvia hispanica L.) é uma planta nativa da região centrooeste do México até o norte da Guatemala. Antigamente as sementes de chia foram amplamente utilizadas por tribos astecas, principalmente como alimento e também como na medicina e para a fabricação de tintas, mas hoje é comercializada em diversos lugares do mundo. A semente de chia tem ganhado destaque comercialmente por ser considerada uma boa fonte de compostos de óleo, proteínas, fibras, minerais e polifenólicos. A semente de chia tem ganhado destaque comercialmente por ser considerada uma boa fonte de compostos polifenólicos, proteínas, fibras e minerais. Este trabalho teve como objetivo analisar os rendimentos da extração do óleo de chia, através de diferentes tempos e solventes na extração. A metodologia utilizada para extração do óleo foi via Soxhlet variando o tipo de solvente, hexano e álcool de cereal, em relação ao tempo de 2 horas e 4 horas, conforme o planejamento fatorial completo $2^{2}$. Analisando o rendimento de óleo, verificou-se que o melhor resultado foi obtido através do solvente álcool de cereais com o maior tempo de extração (4 horas), sendo este de aproximadamente de $39,5 \%$ de óleo de chia. O resultado se mostrou satisfatório, pois ao comparar com a literatura que apresenta o rendimento do óleo entre $25 \%$ a $38 \%$ o encontrado nesta extração foi maior.
\end{abstract}

\section{INTRODUÇÃO}

Os produtos de origem natural, como por exemplo, óleos essenciais, revelam-se como importantes matérias-primas para diversos ramos industriais. Segmentos da indústria de cosméticos, farmacêuticos e alimentícia demonstram grande interesse no desenvolvimento de novos produtos aplicando estes óleos, em especial nos componentes de ação terapêutica de plantas medicinais. Muitos desses óleos, além de conferir características sensoriais, apresentam também propriedades nutricionais, antioxidantes ou antimicrobianas

A chia (Salvia hispanica L.) é uma planta herbácea anual que pertence à família Lamiaceae (Ayerza, 1995; Marineli et al., 2014), é nativa da região que se estendia do centrooeste do México até o norte da Guatemala. Suas sementes foram amplamente utilizadas por tribos astecas, principalmente como alimento, na medicina e também para a fabricação de tintas (Coates e Ayerza, 1996). 
O uso da chia pode ser na forma de farinha de sementes inteiras, mucilagem, e óleo da semente, está por sua vez, tem sido descrita como uma boa fonte de proteínas, fibras, minerais e polifenólicos (Reyes-Caudillo, Tecante, Valdivia-López, 2008). Além disso, a semente e óleo de chia contém um conjunto rico de antioxidantes naturais, aminoácidos essenciais, além de fibras, potássio, cálcio e ômega 3 (Alvarez-Chavez et al., 2008; Ixtaina et al., 2011; apud Marineli, 2014; Júnio e Lemos, 2012) que protegem os serem humanos contra muitas doenças e também promove efeitos benéficos na saúde humana (Nijveld et al., 2001; apud Marineli, 2014).

O óleo de chia, com cerca de $25 \%$ a $38 \%$ de óleo por peso (Ayerza, 1995), e pode ser obtido por diferentes métodos, tais como extração por solvente, prensagem e por extração supercrítica com solventes como dióxido de carbono (Ixtaina et al., 2011; Rocha et al., 2011; apud Martínez, 2011). Uma vez que o óleo de semente de chia é um produto natural, que tem uma composição química variável, depende de vários fatores tais como o ambiente de cultivo e o sistema de extração. A forma de extração pode influenciar nas propriedades da semente, e estas propriedades são frequentemente essenciais para o desenvolvimento de equipamentos para o manuseamento, transporte, secagem, armazenamento e outros processos, tais como a extração do óleo (Kachru, Gupta e Alam, 1994; apud Ixtaina, Nolasco e Tomás, 2008).

Assim, em vista de sua potencial aplicação, é importante estudar formas de otimizar a extração do óleo. Dentro deste contexto, o objetivo deste trabalho foi analisar o rendimento de óleo de chia, através da técnica de extração por solvente, avaliando o tipo de solvente e o tempo necessário para extração.

\section{MATERIAL E MÉTODOS}

Os experimentos foram realizados no laboratório de Química Geral e Inorgânica da Universidade Comunitária da Região de Chapecó - UNOCHAPECÓ. Inicialmente a amostra da semente de chia foi triturada em um liquidificador (BRITÂNIA - LQ - Bellagio V5) por aproximadamente 1 minuto. Depois de triturada pesou-se $10 \mathrm{~g}$ da amostra em balança analítica (QUIMIS - ISA. 210), a qual foi empacotada em um cartucho de extração, para evitar perdas da amostra com o processo.

Após a secagem dos balões de fundo chato contendo pérolas de vidro por 1 hora a $105^{\circ} \mathrm{C}$ na estufa (FLUXO - 016132), montou-se o aparato de extração do tipo Soxhlet, contendo o cartucho da amostra no extrator. Realizou-se um planejamento experimental para as extrações, utilizando o software Statistica 7.0 (StatSoft $\left.{ }^{\circledR}\right)$. O planejamento foi um fatorial completo $2^{2}$ em duplicata, com dois solventes diferentes: hexano (B) (LABSYNTH) e álcool de cereais (A) (LABSYNTH), e com variação no tempo de 2 e 4 horas, conforme dados da segunda e terceira coluna da Tabela 1. Após as diferentes extrações, procedeu-se a evaporação do solvente pelo evaporador rotativo (TECNAL - TE-211). Posteriormente os balões foram pesados na balança analítica para então realizar a quantificação da massa do óleo de chia presente na extração.

Os resultados do planejamento experimental foram analisados com auxílio do software Statistica 7.0 (StatSoft $\left.{ }^{\circledR}\right)$. Para avaliação das influências das variáveis independentes, tipo de solvente e tempo de extração, sobre a variável de resposta, quantidade de óleo extraído, utilizou-se a ANOVA com $95 \%$ de confiança. 


\section{RESULTADOS E DISCUSSÃO}

De acordo com os ensaios realizados, verificou-se que o maior rendimento da extração de óleo essencial da semente de chia foi obtido no maior tempo (4 horas) e com o solvente álcool de cereais, onde obteve-se um rendimento médio de $3,8626 \mathrm{~g}$, sendo que o rendimento de óleo obtido por todos os ensaios variou entre $2,8788 \mathrm{~g}$ a $4,0438 \mathrm{~g}$ conforme demonstrado na Tabela 1.

Tabela 1 - Matriz do planejamento fatorial completo $2^{2}$ com valores reais e codificados, e o rendimento do óleo de chia após extração (duplicata)

\begin{tabular}{ccccc}
\hline \multirow{2}{*}{ Ensaio } & Tempo (horas) & Solvente & \multicolumn{2}{c}{ Rendimento $(\mathrm{g})$} \\
\hline 1 & $2(-)$ & Álcool de cereais (-) & $3,4295(5)^{*}$ & $3,4106(7)^{*}$ \\
2 & $4(+)$ & Álcool de cereais (-) & $4,0438(6)^{*}$ & $3,8626(8)^{*}$ \\
3 & $2(-)$ & Hexano (+) & $2,9511(3)^{*}$ & $2,8788(4)^{*}$ \\
4 & $4(+)$ & Hexano (+) & $3,2238(1)^{*}$ & $3,2840(2)^{*}$ \\
\hline
\end{tabular}

*Os números entre parênteses estão relacionados com a ordem aleatória dos experimentos.

Através dos dados da Tabela 1, pode-se determinar quais parâmetros são significativos para a extração do óleo, conforme demonstra a Tabela 2.

Tabela 2 - Coeficientes de regressão, erro padrão, $t$-Student e $p$-valor para o planejamento fatorial completo $2^{2}$.

\begin{tabular}{cccrc}
\hline Fatores & Efeitos & Erro padrão & t-Student & p-valor \\
\hline Média & 3,3855 & 0,0256 & 132,0914 & 0,0000 \\
1 Tempo & 0,4360 & 0,0513 & 8,5066 & 0,0010 \\
2 Solvente & $-0,6022$ & 0,0513 & $-11,7479$ & 0,0003 \\
1 by 2 & $-0,0971$ & 0,0513 & $-1,8943$ & 0,1311 \\
\hline
\end{tabular}

Compreende-se que os dados significativos devem possuir $\mathrm{p}<0,05, \log$ o observou-se, pela Tabela 1, que os parâmetros tempo e solvente foram significativos neste estudo. Esse resultado já era o esperado, visto que quanto maior o tempo de extração, maior é o tempo que o solvente ficará em contato com a semente, logo a tendência é que se extraia mais óleo, até atingir o equilíbrio de massa, ou até que todo o óleo seja extraído da semente. Quanto ao solvente, as propriedades químicas dos dois solventes são diferentes, o álcool de cereal é um solvente fortemente polar e o hexano é apolar, portanto é esperado que um dos solventes apresente maior afinidade pelo extrato. A partir da análise dos resultados, obteve-se o modelo codificado conforme Equação 1, onde (t) equivale ao tempo de extração em horas e (S) é o tipo de solvente.

$$
\text { Rendimento }(g)=3,3855+0,2180 t-0,3011 S \text { ? }
$$

A Tabela 3 apresenta a análise de variância (ANOVA) através da qual analisou-se a qualidade de ajuste do modelo codificado representado na Equação 01. 
Tabela 3 - Análise de variância (ANOVA) para o modelo codificado.

\begin{tabular}{ccccc}
\hline Fonte de variação & Soma dos Quadrados & g.l & Média Quadrática & $\mathrm{F}_{\text {teste }}$ \\
\hline Regressão & 1,1055 & 2 & 0,5528 & 69,1 \\
Resíduo & 0,0399 & 5 & 0,0080 & \\
Total & 1,1454 & 7 & & \\
\hline
\end{tabular}

$\mathrm{F}_{2 \text { e } 5 ; 95 \%}=5,79 ; \mathrm{R}^{2}=96,52 \%$

Conforme a Tabela 3, o valor de F calculado é aproximadamente doze vezes maior que o F tabelado $(5,79)$, comprovando assim, que o modelo descrito na Equação (1) é preditivo. Ainda de acordo com esta tabela, o coeficiente de explicação $\left(\mathrm{R}^{2}\right)$ é igual a 0,9652 , ou seja, o modelo explica $96,52 \%$ das respostas preditas pelo mesmo.

Conforme o modelo encontrado verificou-se que ao passar do nível inferior para o nível superior de tempo de extração, ou seja, passando de $2 \mathrm{~h}$ para $4 \mathrm{~h}$, obtém-se um aumento no rendimento da extração do óleo essencial próximo a $0,4360 \mathrm{~g}$. Ao avaliar o tipo de solvente observou-se uma variação no rendimento de $0,3011 \mathrm{~g}$ do solvente A quando comparado com o solvente B. Este comportamento pode ser observado na Figura 1.

Figura 1 - Superfície de resposta para o rendimento de óleo essencial relacionando com o tempo de extração e o tipo de solvente.

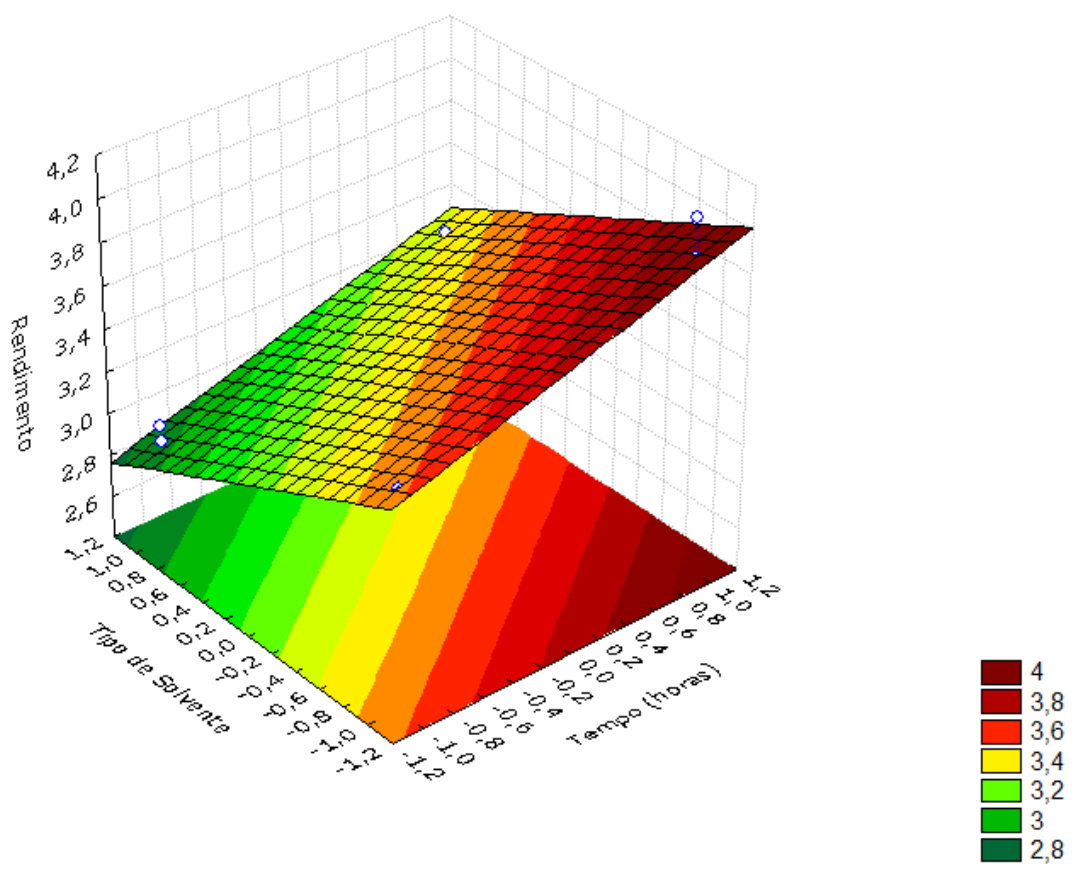

Sabe-se que em processos de extração, pode-se não somente extrair o óleo desejado mas também outros compostos. Desta forma para ter certeza da quantidade de óleos essenciais 
extraídos, faz-se necessário um estudo completo, para qualificar e quantificar os principais compostos extraídos, sendo que o mesmo já está em andamento.

Segundo Ayerza (1995) a chia tem cerca de 25 a 38\% de óleo por peso, realizando a extração do óleo por prensagem em base seca. Analisando os resultados do autor com o presente trabalho observa-se uma coerência, pois obteve-se cerca de $30 \%$ extrato, ou seja, aproximadamente 3,9532g (média da duplicata) de óleo com a extração por solvente álcool de cereal com o maior tempo.

A quantidade extraída foi maior quando utilizou-se o solvente álcool de cereal, tal fato pode ser justificado, pois, segundo Carvalho (2007), a maior parte dos compostos fenólicos não são encontrados no estado livre na natureza, mas sob a forma de ésteres ou heterosídeos sendo, portanto, solúveis em água e em solventes orgânicos polares, ou seja, para o álcool de cereal, neste estudo.

\section{CONCLUSÃO}

O objetivo da extração do óleo de chia, através da técnica de extração por solvente, foi alcançado, dado que os resultados encontrados ficaram coerente ao da literatura. $\mathrm{O}$ maior rendimento obtido neste trabalho foi da extração com o tempo máximo de 4 horas e com o solvente álcool de cereais, onde o rendimento obtido foi de 3,9532g. As vantagens da extração com o solvente álcool de cereais é que além de obter o maior rendimento, esse tipo de solvente não é considerado tóxico, já o hexano tem um nível de toxicidade relevante podendo causar problemas a saúde humana. Com isso, o álcool de cereais torna-se uma boa alternativa para a indústria alimentícia e farmacêutica.

\section{REFERÊNCIAS}

AYERZA, R. Oil content and fatty acid composition of chia (Salvia hispanica L.), from five northeastern locations in northwestern Argentina. Journal of the American Oil Chemists' Society, v. 72, p. 1079-1081, 1995.

CARVAlHO, L. M.; SILVA, R. B.; SILVA, M. M.; CARCARÁ, V, A. K.; AMORIM, R.R. Estudo comparativo entre a quantidade de fenólicos totais presentes em folhas e cálices de Hibiscus sabdariffa L. VII CONEEPI - Congresso Norte Nordeste de Pesquisa e Inovação. Tocantins, 2012.

COATES, W.; AYERZA, R. Production potential of chia in north-western Argentina. Industrial Crop Production, v. 5, n. 3, p. 229-233, 1996.

IXTAINA, V. Y.; MARTÍNEZ, M. L.; SPOTORNO, V.; MATEO, C. M.; MAESTRI, D. M.; DIEHL, B. W. K.; NOLASCO, S. M.; TOMÁS, M. C. Characterization of chia seed oils obtained by pressing and solvent extraction. Journal of Food Composition and Analysis, v. 24, p. 166-174, 2011.

IXTAINA, V. Y.; NOLASCO, S. M. e TOMÁS, M. C. Physical properties of chia (Salvia hispanica L.) seeds. Industrial crops and products, v. 28, p. 86-293, 2008. 
JÚNIO, H. P. L.; LEMOS, A. L. A. Chia (Salvia hispanica). Diagn Tratamento, v. 17, n. 4, p.180-182, 2012.

MARINELI, R. S.; MORAES, É. A.; LENQUISTE, S. A.; GODOY, A. T.; EBERLIN, M. N.; MARÓSTICA, M. R. Jr. Chemical characterization and antioxidant potential of Chilean chia seeds and oil (Salvia hispanica L.). LWT - Food Science and Technology, v. 59, p. 1304$1310,2014$.

MARTÍNEZ, M. L.; MARÍN, M. A.; FALLER, C. M. S.; REVOL, J.; PENCI, M. C.; RIBOTTA, P. D. Chia (Salvia hispanica L.) oil extraction: Study of processing parameters. LWT - Food Science and Technology, v. 47, p. 78-82, 2012.

REYES-CAUDILLO, E.; TECANTE, A.; VALDIVIA-LÓPEZ, M. A. Dietary fibre content and antioxidant activity of phenolic compounds present in Mexican chia (Salvia hispanica L.) seeds. Food Chemistry, v. 107, p. 656-663, 2008. 